\title{
CORRELATIVE ANALYSIS OF THE RELATIONSHIP BETWEEN CHANGES IN SURFACE SOLAR RADIATION AND HAZE POLLUTION (ATMOSPHERIC TURBIDITY INDEX) IN BEIJING FROM 1961 TO 2011
}

\author{
QI Y. ${ }^{1}$ \\ FANG S.B. ${ }^{2}$ \\ WANG R.Y. ${ }^{1}$ \\ ZHAO H. ${ }^{1}$ \\ WANG H.L. ${ }^{1}$ \\ ZHANG K. ${ }^{1}$ \\ YU W.G. ${ }^{2}$
}

\author{
${ }^{1}$ Gansu Key Laboratory of Arid Climatic Change and Reducing Disaster \\ Institute of Arid Meteorology \\ China Meteorological Administration \\ Lanzhou, 730020, China \\ ${ }^{2}$ Institute of Eco-environment and Agro-meteorology \\ Chinese Academy of Meteorological Sciences, Beijing, China, 100081
}

Received: 21/10/2015

Accepted: 30/11/2015

Available online: $21 / 01 / 2016$ *to whom all correspondence should be addressed: e-mail: fangshibo@camscma.cn

\begin{abstract}
Increased aerosol or haze is the reason that solar radiation decreases, but there is no evidence to support this theory. This research aims to quantitatively analyze the contribution of air pollution to surface solar radiation (SSR) reduction in Beijing. Because there is no long-term serial ground observational aerosol data, in order to reflect the atmospheric pollution and aerosol levels, we developed an atmospheric turbidity index (ATI).Monthly and annual variations in the ATI are significantly correlated with aerosol optical depth (AOD), and ATI could well reflect the change of air pollution. The ATI and SSR are significantly negatively correlated. The changes in the Beijing SSR presented a clear decreasing trend. From the inter-annual variability, the SSR exhibited a rapidly declining trend from 1960 to approximately1990 and a gradual increasing trend after 1990. The atmosphere turbidity index in the Beijing area was the main factor which indicated the change in SSR.
\end{abstract}

Keywords: Surface Solar Radiation, Atmospheric Turbidity Index, Atmospheric pollution, Haze pollution

\section{Introduction}

In the past half century, many studies have analyzed and discussed various regional and global terrestrial surface solar radiation (SSR)variations and their influencing factors by analyzing observed radiation data (Wild et al., 2005; IPCC 2007; Ding et al., 2014; Qi et al., 2014). The results of these studies showed that SSR decreased by approximately 10\% from 1960 to 1990 during a period known as the "Global dark"; since the late 1980s, SSR has started increasing in many regions, which is known as the "Global brighten" (Wild et al., 2005). Wang et al. (2010) observed the relationship between radiation change and atmospheric haze (aerosol content) in China. Haze is an atmospheric phenomenon that is characterized by visibility of less than $10 \mathrm{~km}$ due to complex material that is suspended in the air, such as dust, smoke and other fine particles (Zhuang et al., 2014). When haze occurs, there must be the existence of aerosols. However, when aerosols exist in the air, there is not necessarily appeared haze. In addition to the adverse health effects in humans, haze induced urban and nonurban haze can change the radiation balance of the earth, damage forests and crops, and contaminate lakes and rivers (Zhuang et al., 2014). Previous research showed the 
appearance of haze made to reduce solar radiation reaching the ground. The study by Qi et al. (2015) showed that haze pollution / aerosol air pollution is the main factor contributing to the reduction of SSR in the eastern region of China. Thus, the main reason for this decrease is an increase in total suspended particles in the atmosphere. These studies suggested that increased aerosol or haze was the reason for a reduction in radiation, but there is no evidence to support this theory.

Because there were no long-term serial ground observational aerosol data, direct radiation and scattering radiation were used to obtain the atmospheric turbidity index, which reflects atmospheric pollution and aerosol levels. The haze in Beijing has increased in recent years; determining whether the haze weather could reduce SSR requires further evidence. In this study, the annual variation of SSR in Beijing from 1961 to 2011was investigated based on available surface solar radiation data. To quantitatively analyze the contribution of air pollution to changes in SSR, identifying the correlation between SSR and air pollution was the primary aim of this study.

\section{Data and methods}

\subsection{Data}

The SSR data used in this paper were collected from the site $\left(39.8^{\circ} \mathrm{N}, 116.28^{\circ} \mathrm{E}\right)$ in Beijing, China, over the entire 1961-2011 period, including direct and diffuse radiation measurements. In addition to SSR data, conventional meteorological data were obtained from the same Beijing sites, including precipitation, sunshine percentage, sunshine duration, temperature, total cloud cover, and low cloud cover. The aerosol optical depth (AOD) data over Beijing were from the MODIS Land Standard Products MOD08_M3 by NASA during the 2001-2012 periods.

\subsection{Methods}

\subsubsection{The atmospheric turbidity Index (ATI)}

This study calculated atmospheric turbidity index using meteorological observational data due to the short time series of aerosol data. Atmospheric turbidity reflects the change in aerosol content (Qi et al., 2015). We developed methods to measure the atmospheric turbidity index (ATI) based on direct solar radiation (DSR) and diffuse radiation (DR). ATI was formulated as:

$\mathrm{ATI}=\frac{\mathrm{DSR}}{\mathrm{DR}}$

The atmospheric turbidity mainly depends on the content of atmospheric aerosols under the same solar altitude on a sunny day. The ATI value is very small when the atmosphere is clean (low aerosol content), and higher atmospheric turbidity corresponds to greater ATI values. The relationship between atmospheric turbidity and surface solar radiation (SSR) is defined in the following equation.

$$
\mathrm{SSR}=\mathrm{DSR}+\mathrm{DR}
$$

By comparing formula (1) with formula (2), the following was found:

$$
\frac{\mathrm{SSR}}{\mathrm{ATI}}=\mathrm{DR}+\frac{\mathrm{DR}}{\mathrm{DSR}}
$$

$S S R / A T I$ and $D R$ are quadratic equations, and the SSR and ATI are two non-independent variables. The SSR and ATI were tested by the MODIS Land Standard Products MOD08_M3 (Level-3 MODIS Atmosphere Daily Global Product).

\subsubsection{Trend analysis, significance Test}

The annual time-series of the indices were calculated for each station. The annual variation trends of the indices were estimated using linear trends for each station, incorporating all available years within the 
1961-2011 timeframe. Using the statistical significance test, the trends were evaluated at the $5 \%$ level against the null hypothesis (Wei, 2007).

\section{Results and discussion}

\subsection{The AOD and ATI relation shipanalysis}

The monthly variation patterns of the ATI and AOD of Beijing from 2000 to 2011 are shown in Figure1. The variations in the trends of the ATI and AOD are roughly the same. The ATI and AOD values are lower in autumn and winter than in other seasons. From the average annual variation, the highest values of ATI and AOD were observed in 2008, and the lowest values were observed in 2004. Both the monthly and annual ATI and AOD are significantly correlated, with a correlation coefficient of 0.285/0.541 using the significance test at the $0.01 / 0.05$ level. Thus, the atmospheric turbidity can be used to reflect atmospheric conditions.
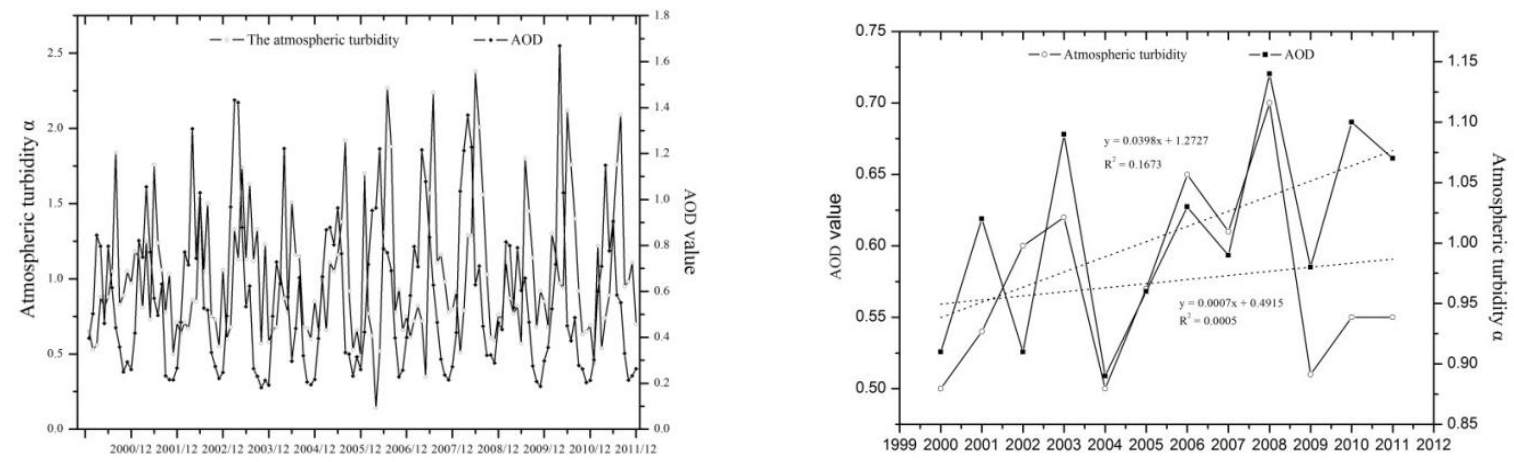

Figure 1. The monthly (left) and annual (right) average distributions of ATI and aerosol optical depth AOD $(550 \mathrm{~nm})$ from 2000 to 2011 in Beijing

\subsection{Relations between SSR and meteorogical elements}

The meteorological factors significantly affect SSR variation. Several existing studies (Chen et al., 2005; Che et al., 2006; Zhang et al., 2004; Elminir et al., 2006) have shown that the aerosol factor due to human activities is the main factor influencing SSR variation. Shao et al. (2009) found that SSR decreased with the increase of PM10 concentration in North China.

The correlation coefficients between precipitation, low cloud cover, total cloud cover, sunshine percentage, atmospheric turbidity and SSR are presented in Table 1.From 1961 to 2011, the correlation relationship between SSR and low cloud cover and turbidity are negative. During this time period, the simple correlation coefficient of these variables passed the 0.01 significance level test. There were no significant correlations between SSR and precipitation, total cloud cover. The ATI and SSR demonstrate a significant negative correlation relationship.

Table1. The simple correlation coefficients of SSR and climatic factors.

\begin{tabular}{cccccc}
\hline & Precipitation & $\begin{array}{c}\text { Sunshine } \\
\text { percentage }\end{array}$ & $\begin{array}{c}\text { Low cloud } \\
\text { cover }\end{array}$ & $\begin{array}{c}\text { Total cloud } \\
\text { cover }\end{array}$ & $\begin{array}{c}\text { Atmospheric } \\
\text { turbidity }\end{array}$ \\
\hline $\begin{array}{c}\text { Simple } \\
\text { correlation }\end{array}$ & -0.131 & $0.793^{* *}$ & $-0.577^{* *}$ & -0.133 & $-0.530^{* *}$ \\
\hline
\end{tabular}

*Values significant at a 0.01 probability level

\subsection{The relationship between ATI and SSR}

Aerosols are important components that can result in changes in SSR (Qi et al., 2014; Qi et al., 2015; Zhang et al., 2004). Because there are no long-term serial ground observational aerosol data, direct radiation and 
scattering radiation were used to determine the ATI, which reflects the atmospheric pollution and aerosol levels. Zhang et al. (1997) studied the relationship between solar radiation and changes in air pollution in cities and found that the trend of change of the ATI can reflect changes in atmosphere pollutants well. The increase in atmospheric turbidity by an average of $0.036 / 10 \mathrm{a}$ is attributed to the aerosol content, which caused SSR to decrease (Figure 2).The atmospheric turbidity and SSR were significantly negatively correlated, which can be seen from partial and simple correlations (table 2). This result showed that among the many factors that resulted in the decrease in SSR, the atmosphere turbidity index in the Beijing area was the main factor.

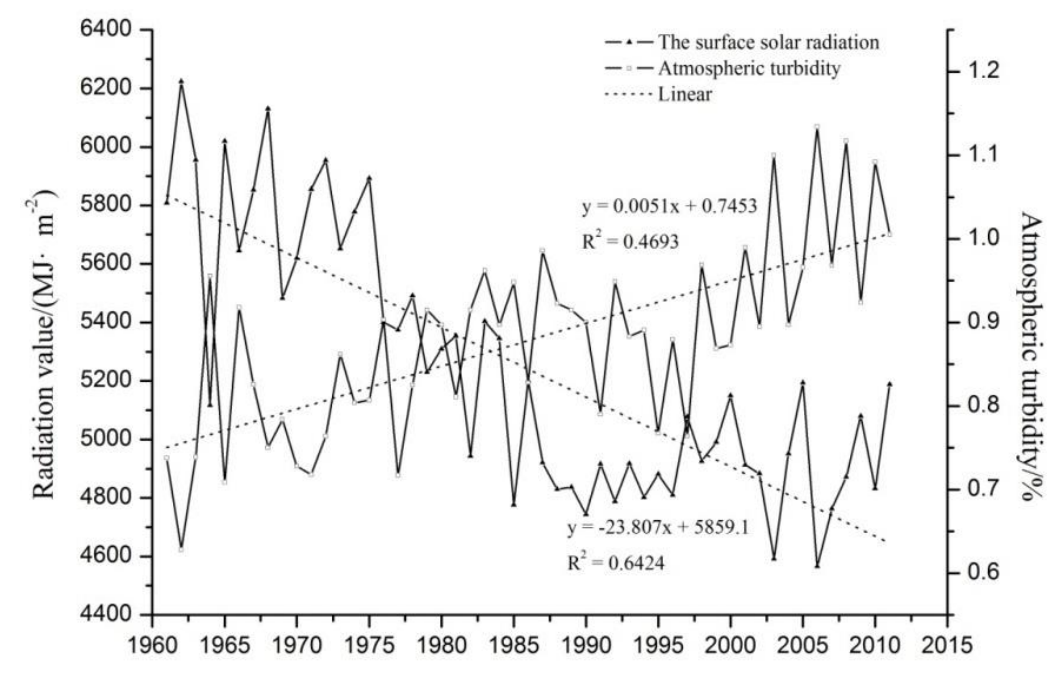

Figure2. The distributions of SSR and ATI from1961 to 2011 in Beijing

\section{Conclusions}

This study analyzed the annual variation in SSR in Beijing during the 1961-2011 period and the correlation between SSR and atmospheric pollution. The variations in SSR and AOD are very small and decreased slightly over Beijing. Yet, SSR and AOD were significantly correlated. The changes in trends of the ATI and AOD were similar. The monthly and annual ATI and AOD were significantly correlated, so the atmospheric turbidity could reflect the atmospheric conditions well. The average changes in the SSR in Beijing exhibited a downward trend; the inter-annual Beijing SSR was different for each year and showed a decreasing trend. From the inter-annual variation, SSR decreased prior to the 1990s before transitioning to a trend that slowly increased. Among all of the factors that influenced the change in SSR, the atmosphere turbidity index in the Beijing area was the main factor.

\section{Acknowledgements}

This research was supported by the National Natural Science Foundation of China (41505098), China Special Fund for Meteorological Research in the Public Interest(Major projects) (GYHY201506001-2).

\section{References}

Chen Z.H. Shi G.Y. and Che H.Z (2005), Analysis of the solar radiation of Xinjiang Uygur Autonomous Region in recent 40 years, Arid Land Geography, 28, 734-739.

Che H.Z., Shi G.Y., Zhang X.Y., Zhao J.Q., and Li Y. (2006), Analysis of sky conditions using 40 years record of solar radiation data in China, Theoritical and Applied Climatology, 89, 83-94.

Ding Y.H. and Liu Y.J. (2014), Analysis of long-term variations of fog and haze in China in recent 50 years and their relations with atmospheric humidity, Science China: Earth Sciences, 44, 37-48 
Elminir H.K. (2006), Relative influence of weather conditions and air pollutants on solar radiation Part 2: Modification of solar radiation over urban and rural sites, Meteorology and Atmospheric Physics, 96, 257-264.

IPCC. Climate Change 2007: The Physical Science Basis. (2007) United Kingdom and New York, NY, USA: Cambridge University Press, Cambridge, 996.

Qi Y., Fang S.B. and Zhou W.Z. (2014), Variation and spatial distribution of surface solar radiation in China over recent 50 years, Acta Ecologica Sinica, 34, 7444-7453.

Qi Y., Fang S.B. and Zhou W.Z. (2015), Correlative analysis between the changes of surface solar radiation and its relationship with air pollution, as well as meteorological factor in East and West China in recent 50 years, Acta Physica Sinica, 64, 089201.

Shao Z.Y., Zhou T., Shi P.J. and Gong D.Y. (2009), Spatial Temporal Characteristics of the Influence Atmospheric Pollutanton Surface Solar Radiation Changes for Chinese Key Cities, Plateau Meteor., 28, 1105-1114.

Wild M., Gilgen H., Roesch A., Ohmura, A., Long, C.N., Dutton E.G., Forgan B., Kallis A., Russak V. and Tsvetkov A., (2005) From dimming to brightening: Decadal changes in solar radiation at Earth's surface, Science, 308, 847-850.

Wei F.Y. (2007) The technologies of statistics diagnosis and forecast in modern climate. 2nd edition, Beijing: Meteorology Press.

Wang K., Ye H., Chen F., Xiong Y.Z., Li X.Y.. and (2010) Long-term change of solar radiation in southeastern China: Variation, factors, and climate forcing, Ecol. Environ. Sciences, 19, 1119-1124.

Zhang W.Y., Feng G.H., Miao Y. Z. and Ren J.M. (1997) The Discussion on the changing Relation between the Solar Radiation and the Atmospheric Pollution in Lanzhou, Gansu Meteor., 15, 43-44, 54 .

Zhang Y.L., Qin B.Q. and Chen W.M. (2004) Analysis of 40 year records of solar radiation data in Shanghai, Nanjing and Hangzhou in eastern China, Theoritical and Applied Climatology, 78, 217-227.

Zhuang X.L., Wang Y.S., He H., Liu J., Wang X., Zhu T., Ge M., Zhou J., Tang G. and Ma J. (2014), Haze insights and mitigation in China: An overview, Journal of Environmental Sciences, 26, 2-12. 